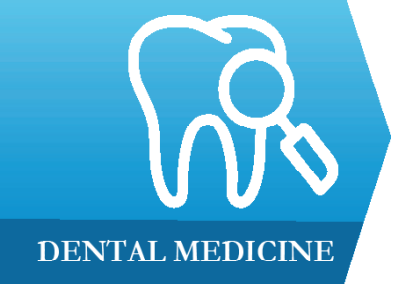

1) Department of Prosthodontics, Iuliu Hatieganu University of Medicine and Pharmacy, ClujNapoca, Romania

2) Department of Odontology, Endodontics and Oral Pathology, Iuliu Hatieganu University of Medicine and Pharmacy, Cluj-Napoca, Romania
DOI: $10.15386 / \mathrm{mpr}-1148$

Manuscript received: 26.08 .2018

Received in revised form: 17.05.2019 Accepted: 09.06.2019

Address for correspondence: rchisnoiu@yahoo.com

\title{
Dentists' perspectives on the reconstruction possibilities of a non-vital tooth
}

Andrea Chisnoiu ${ }^{1}$, Alina Picos ${ }^{1}$, Liana Lascu ${ }^{1}$, Marius Negucioiu ${ }^{1}$, Radu Chisnoiu ${ }^{2}$, Andreea Kui ${ }^{1}$

\begin{abstract}
Background and aims. The decision-making process when restoring a non-vital tooth is influenced by multiple factors. This study aimed to survey the dentists' preferences regarding cast post-and-core and fiber post techniques for the reconstruction of non-vital teeth and to identify a correlation between reconstruction technique and practitioners characteristics, or dental characteristics.
\end{abstract}

Methods. The survey instrument was a questionnaire, which included a general part with questions regarding the practitioner's profile (gender, age, years of experience, pattern and location of practice, etc.) and the dental characteristics (anterior or posterior position of the tooth on the arch, the amount of dental remaining tissues, etc.) and a technical part, containing more specific questions regarding the manufacture and performance of root-coronal reconstructions.

Results. Among the surveyed practitioners ( $\mathrm{n}=35), 69.7 \%$ use more often cast postand-core reconstructions (CPR) while $30.3 \%$ choose fiber post reconstructions (FPR). No difference in the reconstruction type was observed regarding patient's age $(p=0.23)$ or gender $(p=0.092)$. The para-function criterion was considered important by $8.23 \%$ of the participants. When deciding the type of the root-coronal reconstruction depending on the remaining dentine walls, CPRs are significantly more frequently used in posterior areas $(\mathrm{p}=0.043)$ or when para-functional habits exist $(\mathrm{p}=0.022)$.

Conclusion. Cast post-and-core represent the most frequently used type of reconstruction for non-vital teeth. Fiber post reconstructions are indicated in the aesthetic zone and when the amount of healthy remaining dental structure is higher.

Keywords: non-vital teeth, reconstruction, fiber post, cast post-and-core

\section{Background and aims}

Over the past century, treatment options for the non-vital teeth have evolved greatly. Modern concepts regarding the treatment of non-vital teeth is influenced by multiple factors that may affect the prognosis such as caries, cusps fractures, trauma, the endodontic access and instrumentation and decreased moisture [1]. Although there is an abundance of literature on this topic, the decision should be made after a complete examination of the oral cavity, using a precise protocol that would integrate all data about tooth characteristics; as a result of this analysis, the practitioner would choose between two types of root-crown reconstructions - the use of a cast post-and-core or a fiber post [2].
New research has revealed information about the biomechanical and physiological properties of a non-vital tooth. As the predominant cause of failure of reconstructions on endodontically treated teeth is fracture, the mechanical resistance to this event being directly related to the amount of healthy dentin remaining [3]. An important factor that influences the risk of fracture represents the state of dentine hydration. The results presented by Papa et al. [4] have showed that there is a small difference between dentine water concentrations: $12.35 \%$ for the vital teeth, comparing to $12.10 \%$ for the devitalized teeth. But regarding this aspect, other studies suggest that for a non-vital tooth, the dentine degree of hydration is lower than for a vital tooth, 
so the tooth would be more predisposed to fracture [5].

In clinical practice, usually 2 types of root-coronal reconstruction can be distinguished: the direct method (manufactured fiber post and composite restoration material) and the indirect method (cast post-and core obtained in dental laboratory) [4].

New materials and therapeutic options based entirely on adhesion are nowadays available, such as endocrowns and $\mathrm{CAD} / \mathrm{Cam}$ manufactured post and cores [6]

Cast metal posts were traditionally used for intraradicular retention and have shown high survival rates. Gomez-Polo et al. reported a 10 years survival rate of 82.6 for cast metal posts [7].

Fiber posts (glass or carbon) are nowadays frequently indicated in tooth reconstruction, transforming the use of cast metal posts in a secondary treatment alternative. Piovesan et al. reported a 97-month survival rate of $90.2 \%$ for fiber post restorations [8]. Fiber post systems present several advantages, such as similar mechanical properties to those of dental structures, resulting in similar behavior in occlusal force distribution as those of natural healthy teeth and also require a more conservative preparation of the root $[5,9]$. Conventional cast post-and cores present several disadvantages such as root fractures [10] or loss of retention [7,11]. Stress concentration in the post and higher dentin strain have been verified in teeth restored with cast post-and-core and other metallic posts [12]. An in vitro study realized by Sonkesriya et al. showed that the fracture resistance was higher for glass fiber posts (mean=1213.2 $\mathrm{MPa}$ ) compared to custom made metal posts $(\mathrm{mean}=857.4 \mathrm{MPa})$ [13].

However fiber reinforced posts are also exposed to failure, which can be related to the amount of residual coronal structure [14]. A prospective study [15] showed that type of post-and-core was not relevant with respect to survival, but the amount of remaining dentin after preparation influenced significantly the longevity of postand-core restoration. The ferrule adds some retention, but primarily provides a resistance from and enhances longevity to the endodontically treated teeth restored with post and crown. A minimum of $1.5-2 \mathrm{~mm}$ ferrule of dentin has been consistently described as an essential factor for the success of fiber post systems [16]. In the absence of coronal ferrule, Fokkinga et al. [17] suggested to use cast post-and-core.

Cast post-and-core technique also presents several advantages. They contain one solid material and do not separate under stress or function. Cast metal posts are best used for those teeth with canals that are elliptical or irregular in diameter. Excessive tooth reduction does not have to be accomplished in order to accommodate a cast post; it will fill all shapes of canals [4,18].
This study aimed to survey the dentists' preferences between cast post-and-core and fibered post techniques for the management of a non-vital tooth requiring a reconstruction. Another objective of the study was to identify whether the use of a certain reconstruction technique is associated with the practitioners characteristics (gender, age, years of experience, pattern and location of practice, etc.) or with dental characteristics (anterior or posterior position of the tooth on the arch, the amount of dental remaining tissues, etc.).

\section{Materials and methods \\ The questionnaire}

The survey instrument was a questionnaire that has been tested among 5 specialists to evaluate and validate the design [12]. After adjustments, the questionnaire was finalized on the basis of two domains as follows:

The questionnaire contained 19 questions, divided in two parts, general and technical part (Table I).

\section{The recruitment of participants}

The dental practitioners invited to participate to our survey were selected randomly within all the four regions of Romania. The distribution of the questionnaires was done by email and the participants were asked to answer the questions via online forms (Google ${ }^{\circledR}$ online forms). Using this method, the answers were automatically inserted into an Excel document.

The questionnaire was distributed to 150 practitioners and data obtained form 35 respondents (response rate 23.3\%; 33 general practitioners and 2 specialists) was validated and statistically analyzed.

\section{Data analysis}

The MedCalc Statistical Software version 15.4 (MedCalc Software, Ostend Belgium; https:// www. medcalc.org; 2015) was used to statistically analyze the data obtained from respondents.

Frequency distribution (for treatment philosophy, as well as standard deviation) was used for the descriptive statistical representation of the results.

The Crobach's Alpha was calculated in order to evaluate the internal consistency of the questionnaire. Mann-Whitney test and Chi-square test were also used. A $\mathrm{p}$ value $<0.05$ was considered significant.

The data obtained from dentists who responded to our survey were statistically analyzed using the MedCalc Statistical Software version 15.4 (MedCalc Software, Ostend Belgium; https:// www.medcalc.org; 2015).

Mann-Whitney test and Chi-square test were used for the analysis of the data. The Crobach's Alpha was calculated in order to evaluate the internal consistency of the questionnaire. A $p$ value $<0.05$ was considered as significant. 
Table I. The questionnaire used to accomplish the present survey.

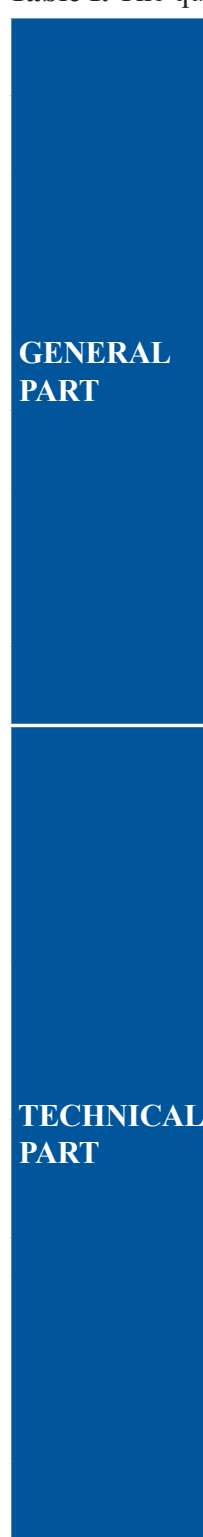

1. What is your main activity?

2. How many years have you been practicing?

3. Do you think a devitalized tooth should be crowned routinely?

4. What type of coronary re-construction do you use most often?

5. Does the patient's age influence your choice of CPR?

6. Do the morphological characteristics of the patient influence the choice of reconstruction?

7. Do para-functional habits have an influence on the choice of reconstruction?

8. For which reconstruction would you opt in case of an aesthetic purpose?

9. Does the price/cost is an important aspect in the choice of treatment plan?

10. Which of the factors influencing the decisionmaking do you consider to be the most important?

1. Which type of restoration would you choose according to the height of healthy tissue on supragingival level (ferrule)?

2. What type of reconstruction would you use in the presence of an adverse occlusal context?

3. Which restoration to choose according to the number of remaining walls?

4. Depending on the sector, do you have a preference for the type of reconstruction?

5. What type of DCR do you use most often?

6. What type of PCR do you use most often?

7. What material do you use most often for DCR cementation?

8. What complications are considered to be most common for PCR?

9. What complications are considered to be most common for DCR?
General practitioner/ Endodontist / Oral Surgeon/ Other $<10$ years $/ 10-20$ years/ $>20$ years

Yes/No

Fibered post reconstruction (FPR)/ Cast post-and-core reconstruction $(\mathbf{C P R})$

Yes/No

Yes/No

Yes/No

FPR / CPR /Other:

Yes/No

Tooth's morphology/ Para-functions/ Aesthetics/ Financial aspects

- If supra-gingival circular height (ferrule) between $2 \mathrm{~mm}$ and $4 \mathrm{~mm}:$ FPR/CPR

- If supra-gingival circular height (ferrule) less than 1.5mm: FPR/CPR

Post-and-core reconstruction (PCR)/dowel-core reconstruction (DCR)

- If there remains a wall: FPR / CPR

- If there are two walls left: FPR / CPR

- If there are three walls left: FPR / CPR

- If all the walls remain: FPR / CPR

Anterior FPR/ Anterior CPR/ Posterior FPR/ Posterior CPR

Metallic/ Ceramic/ Composite

Metal/ Titanium/ Ceramic/ Composite/"Screw-post"/Other: Zinc-phosphate cement/ Polycarboxilate cement/ Resinmodified glass-ionomer cement/ Glass-ionomer cement/ Resin-based cement

Loss of the post/ Fracture/ Dental complications (caries, peri-apical infection, lack of sealing ...)/ Other

Loosening/ Fracture/ Dental causes (caries, peri-apical infection, lack of marginal sealing...)/ Other

\section{Results}

In the first part, responses to the questions in the general section were evaluated. Among the surveyed practitioners, $91.4 \%(\mathrm{n}=33)$ were working in urban and peri-urban areas and $18.6 \%(\mathrm{n}=2)$ in rural areas. Most of the participants presented a working-experience of 10 20 years $(71.4 \%, \mathrm{n}=25)$. No statistical significance was identified between the technique of reconstruction and years of experience or working area.

Regarding the aspects that may influence the decision when choosing between the two types of reconstructions, the practitioners' answers are presented in table II.
Table II. Factors influencing the practitioners decision.

\begin{tabular}{|c|c|c|c|}
\hline Factor & Yes & No & $\mathbf{P}$ \\
\hline Patient's age & $5(15 \%)$ & $30(85 \%)$ & 0.08 \\
\hline $\begin{array}{l}\text { Morphological } \\
\text { characteristics of the } \\
\text { patient }\end{array}$ & $6(16.46 \%)$ & $29(83.54 \%)$ & 0.128 \\
\hline Para-functional habits & $3(8.23 \%)$ & $32(91.77 \%)$ & 0.098 \\
\hline Price & $18(51.4 \%)$ & $9(48.6 \%)$ & 0.1 \\
\hline
\end{tabular}

For the second part of the questionnaire, the statistical analysis showed a significant correlation between the remaining walls and use of fibered posts - the higher number of remaining walls, the use of fibered post reconstruction was chosen more frequently as an option $(p<0.005)$. 
Table III. Technical aspects influencing the reconstruction type.

\begin{tabular}{|c|c|c|c|}
\hline Question & PCR & CPR & $\mathrm{P}$ \\
\hline What type of coronary re-construction do you use most often? & $11(31.5 \%)$ & $24(68.5 \%)$ & 0.085 \\
\hline Which reconstruction would you select for an aesthetic treatment? & $28(80 \%)$ & $7(20 \%)$ & $<0.05$ \\
\hline $\begin{array}{l}\text { Which restoration would you choose according to the height } \\
\text { of healthy tissue on supra-gingival level (ferrule)? }\end{array}$ & $\begin{array}{l}\text { Ferrule } 2-4 \mathrm{~mm}: \\
\quad 27(77.14 \%)\end{array}$ & $\begin{array}{l}\text { Ferrule }<1.5 \mathrm{~mm}: \\
\quad 29(82.85 \%)\end{array}$ & $<0.05$ \\
\hline $\begin{array}{l}\text { What type of PCR would you use in the presence of an adverse } \\
\text { occlusal context? }\end{array}$ & $7(20 \%)$ & $28(80 \%)$ & 0.022 \\
\hline $\begin{array}{l}\text { Which restoration to choose according to the number of remaining } \\
\text { walls? }\end{array}$ & $\begin{array}{l}3 \text { wall: } 30(85.71 \%) \\
\text { all walls: } 32(91.42 \%)\end{array}$ & $\begin{array}{l}1 \text { wall: } 30(85.71 \%) \\
2 \text { walls: } 23(65.71 \%)\end{array}$ & $<0.05$ \\
\hline $\begin{array}{l}\text { Depending on the sector do you have a preference for the type of } \\
\text { reconstruction? }\end{array}$ & Anterior: 24 (69\%) & Posterior: 18 (52\%) & 0.043 \\
\hline
\end{tabular}

A significant association was identified between the value of ferrule $(2-4 \mathrm{~mm})$ and the use of FPR, while in cases of supra-gingival remaining healthy tissue lower than $1.5 \mathrm{~mm}$ CPRs are more frequently used.

When deciding the type of the root-coronal reconstruction depending on the remaining dentine walls, two distinct groups were observed: when only 1 or 2 dentine walls remained, the cast post-and-core reconstruction was preferred, while for the situations with 3 or 4 remaining walls fibered post reconstruction was used (Table III). CPRs are significantly more frequently used in posterior areas and when para-functional habits exist.

A correlation was also observed between the location of the tooth on the arch (the sector) and the type of reconstruction. For the anterior sector practitioners use a FPR, while in the posterior area CPRs are preferred. Metallic alloys are usually the choice for manufacturing the cast post $(n=34,97.14 \%)$.

Regarding the type of cements used for cast post cementation the results showed that $75.8 \%(n=26)$ of the respondents use glass-ionomer cements.

When referring to the complications, which may appear after a fibered post reconstruction, fractures, losing and dental decays were chosen in the same proportions.

\section{Discussion}

Previously, restoring a non-vital tooth was a classic gesture in practice and often resulted in cementing a cast post-and-core and a crown. Our study shows that $87.9 \%$ of dentists surveyed consider that the cast post-and-core reconstruction along with the cementation of a crown should not be systematic. These results are in accordance with the findings of Naumann et al. [19] who, in their research, have found that, in Germany, there is a preference for fiber post systems. Based on the results of the study realized by Sterzenbach et al. [20], adhesive postandcore restoration of non-vital teeth using a proper ferrule design improves their reliability in serving as abutment teeth for prosthetic reconstructions.
In our study, age represents an important factor to be considered when choosing between CPR and FPR reconstruction. A study conducted by Dr. Marc Bolla [21] indicates that the risk of failure for a reconstruction of a non-vital tooth in a patient over 60 years old increases significantly (up to 1.5 times).

One of the advantages when using fiber posts is their transparency that insures adequate aesthetics. Dental composites meet all the required criteria for a post-and-core material: adhesion to dental tissues, adequate mechanical properties and possibility of immediate photo polymerization [22]. The translucent appearance of the fibred reinforced posts is very useful as a light vector [23].

For the anterior sector, FPRs are more frequently used due to higher aesthetic demands and lower masticatory forces; however when coronal destruction is severe and root anchorage is required, CPR is indicated [24].

Adhesion is the method of choice for post-and-core reconstructions for most of the practitioners included in the study. Chemical and mechanical properties and complete ability of sealing the endodontic space, preventing any future bacterial contamination represent their main advantages [25].

According to the answers obtained in our survey, zinc oxy-phosphate cement represents the material of choice for PCR cementation for $6.1 \%$ of respondents, while $9.1 \%$ would choose zinc poly-carboxylate cement. The clinical decline for those two cements over the years was observed by other researchers, the major flaw being the lack of adhesion and low retention through micromechanical anchoring only. Their advantages are a low price and good bactericidal properties due to zinc oxide [26].

On average, the success rate of a root-coronal reconstruction is 8.3 years. The occurrence of complications may be due to secondary caries issues, loss of seal, periapical infection. The complications depend mainly on the technique and the quality of canal preparation or of prosthetic reconstruction [27]. 
FPR fractures are more rare than CPR fractures, probably due to their modulus of elasticity, which is closer in value to dentin [28,29]. Salvi et al. [30] found frequent complications that included root fractures (6.2\%) associated with prefabricated titanium posts. However, Hatzikyriakos et al. [31] observed no significant difference among metallic posts after three years.

There are few clinical studies comparing those two techniques of reconstruction. In vitro studies have compared the two procedures regarding physical properties and resistance to fracture. Zoghieb et al. published a research in 2009 in which the resistance to compression of different root reconstructions was analyzed. The authors concluded that the indirect method was more reliable, as a possible failure by fracture would allow a further reconstruction [32].

The decision-making process when restoring nonvital teeth is a complex process and the practitioner should take into consideration several factors, such as the quantity and quality of tooth structure, tooth position on the arch and its function, the characteristics of the materials used, biocompatibility, corrosion resistance, aesthetics, ease of cementation, etc., but also factors like the practitioner's technical possibilities [9].

\section{Conclusions}

Within the limits of our study, we can conclude that, cast post-and core represent the most frequently used reconstruction for non-vital teeth. Among the tested Romanian group, fiber post reconstructions are indicated in the aesthetic zone and when the amount of healthy remaining dental structure is higher. However the present study included a low number of participants, so further research on larger samples is necessary.

\section{References}

1. Bolla M, Muller Bolla M, Borg C, Lupi-Pegurier L, Laplanche O, Leforestier E. Root canal post for the restoration of root filled teeth. Cochrane Database Syst Rev. 2007;(1):CD004623.

2. Papa J, Cain C, Messer HH. Moisture content of vital vs endodontically treated teeth. Endod Dent Traumatol. 1994;10:91-93.

3. Dietschi D, Duc O, Krejci I, Sadan A. Biomechanical considerations for the restoration of endodontically treated teeth : a systematic review of the literature - Part 1. Composition and micro- and macrostructure alterations. Quintessence Int. 2007;38:733-743.

4. Rosenstiel S, Martin L. Contemporary Fixed Prosthodontics. 4th edition. St. Louis Missouri: Mosby. Inc; 2006: pp. 336-379.

5. Naumann M, Blankenstein F, Dietrich T. Survival of glass fibre reinforced composite post restorations after 2 years-an observational clinical study. J Dent. 2005;33:305-312.

6. Rocca GT, Krejci I. Crown and post-free adhesive restorations for endodontically treated posterior teeth: from direct composite to endocrowns. Eur J Esthet Dent. 2013;8:154-179.

7. Gómez-Polo M, Llidó B, Rivero A, Del Río J, Celemín. A 10-year retrospective study of the survival rate of teeth restored with metal prefabricated posts versus cast metal posts and cores. J Dent. 2010;38:916-920.

8. Piovesan EM, Demarco FF, Cenci MS, Pereira-Cenci T. Survival rates of endodontically treated teeth restored with fiber-reinforced custom posts and cores: a 97-month study. Int J Prosthodont. 2007;20:633-639.

9. Naumann M, Sterzenbac G, Alexandra F, Dietrich T. Randomized controlled clinical pilot trial of titanium vs. glass fiber prefabricated posts: preliminary results after up to 3 years. Int J Prosthodont. 2007;20:499-503.

10. Jung RE, Kalkstein O, Sailer I, Roos M, Hämmerle CH. A comparison of composite post buildups and cast gold postand- core buildups for the restoration of nonvital teeth after 5 to 10 years. Int J Prosthodont. 2007;20:63-69.

11. Balkenhol M, Wöstmann B, Rein C, Ferger P. Survival time of cast post and cores: a 10-year retrospective study. J Dent. 2007;35:50-58.

12. Schmitter M, Rammelsberg P, Gabbert O, Ohlmann B. Influence of clinical baseline findings on the survival of 2 post systems: a randomized clinical trial. Int J Prosthodont. 2007;20:173-178.

13. Sonkesriya S, Olekar ST, Saravanan V, Somasunderam $\mathrm{P}$, Chauhan RS, Chaurasia VR. An in vitro comparative evaluation of fracture resistance of custom made, metal, glass fiber reinforced and carbon reinforced posts in endodontically treated teeth. J Int Oral Health. 2015;7:53-55.

14. Ferrari M, Cagidiaco MC, Goracci C, Vichi A, Mason PN, Radovic I, et al. Long-term retrospective study of the clinical performance of fiber posts. Am J Dent. 2007;20:287-291.

15. Ferrari M, Vichi A, García-Godoy F. Clinical evaluation of fiber-reinforced epoxy resin posts and cast post and cores. Am J Dent. 2000;13:15B-18B.

16. Bateman G, Ricketts DN, Saunders WP. Fibre-based post systems: a review. Br Dent J. 2003;195:43-48.

17. Fokkinga WA, Kreulen CM, Bronkhorst EM, Creugers NH. Up to 17-year controlled clinical study on post-and-cores and covering crowns. J Dent. 2007;35:778-786.

18. Zarow M, Ramírez-Sebastià A, Paolone G, de Ribot Porta J, Mora J, Espona J, et al. A new classification system for the restoration of root filled teeth. Int Endod J. 2018;51:318-334.

19. Naumann M, Neuhaus KW, Kölpin M, Seemann R. Why, when, and how general practitioners restore endodontically treated teeth: a representative survey in Germany. Clin Oral Investig. 2016;20:253-259.

20. Sterzenbach G, Rosentritt M, Meyer-Lueckel H, Bitter K, Naumann M. Failure loads of all-ceramic cantilever fixed dental prostheses on post-restored abutment teeth: influence of the post presence and post position. Eur J Oral Sci. 2018;126:526-532.

21. Bolla M. Restaurer la dent dépulpée Reuil-Malmaison. Espace ID; 2014: pp. 55-69.

22. Couvrechel C, Scharffer C. Depose des restaurations coronoradiculaire avec tenon fibré. Info Dentaire. 2012;7:8-15. 
23. Butz F, Lennon AM, Heydecke G, Strub JR. Survival rate and fracture strenght of endodontically treated maxillary incisors with moderate defects restored with differents post-and-core systems: an in vitro study. Int J Prosthodont. 2001;14:58-64.

24. Bolla M, Bennami V. La reconstitution corono-radiculaire pré-prothétique des dents dépulpés. Reuil-Malmaison: Edition CdP; 1999: pp. 15-45.

25. Valandro LF, Yoshiga S, de Melo RM, Galhano GA, Mallmann A, Marinho CP, et al. Microtensile bond strenght between a quartz fiber post and a resin cement: effect of post surface conditioning. J Adhes Dent. 2006;8:105-111.

26. Guastalla O, Sangare A, Allard Y. Les reconstitutions coronoradiculaires: Problèmes mécanique et solution. Strategie Prothétique. 2006;6(2):121-130.

27. Bolhuis HP, de Gee AJ, Pallav P, Feilzer AJ. Influence of fatigue loading on the performance of adhesive and nonadhesive luting cements for cast post-and-core buildups in maxillary premolars. Int J Prosthodont. 2004;17:571-576.
28. Isidor F, Brøndum K, Ravnholt G. The influence of post lenght and crown ferrule lenght on the resistance to cyclic loading of bovine with prefabricated titanium posts. Int $\mathrm{J}$ Prosthodont. 1999;12:78-82.

29. Sahafi A, Peutzfeldt A, Asmussen E, Gotfredsen K. Retention and failure morphology of prefabricated posts. Int J Prosthodont. 2004;17:307-312.

30. Salvi GE, Siegrist Guldener BE, Amstad T, Joss A, Lang NP. Clinical evaluation of root filled teeth restored with or without post-and-core systems in a specialist practice setting. Int Endod J. 2007;40:209-215.

31. Hatzikyriakos AH, Reisis GI, Tsingos N. A 3-year postoperative clinical evaluation of posts and cores beneath existing crowns. J Prosthet Dent. 1992;67:454-458.

32. Zogheib LV, Saavedra Gde S, Cardoso PE, Valera MC, Araújo MA. Resistance to compression of weakened roots subjected to different root reconstruction protocols. J Appl Oral Sci. 2011;19:648-654. 